\title{
Measurement of right ventricular volume in healthy term and preterm neonates
}

\section{S J Clark, C W Yoxall, N V Subhedar}

Arch Dis Child Fetal Neonatal Ed 2002;87:F89-F94

See end of article for authors' affiliations

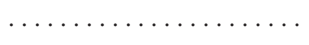

Correspondence to: Dr Clark, Neonatal Unit, Liverpool Women's Hospital, Crown Street, Liverpool L8 7SS, UK; rvecho@yahoo.com

Accepted 4 July 2001
Background: Pulmonary hypertension is associated with worse perinatal outcomes in infants with respiratory disorders. In such infants right ventricular dysfunction may result in poor pulmonary blood flow. Objective: To evaluate the practicability and repeatability of echocardiographic measurements of right ventricular volume in healthy term and preterm neonates, and to follow changes in right ventricular volume over the first 2 days of life.

Methods: Serial echocardiographic examinations were performed on day 0, 1, and 2 on healthy term and preterm neonates. Two methods of estimating right ventricular volume were assessed: the ellipsoid approximation and Simpson's stacked discs methods. Systolic and diastolic volumes on days 1 and 2 were compared with baseline values on day 0 . Term and preterm volumes were compared at the same time points.

Results: Thirty five infants were recruited, 18 term and 17 preterm. Right ventricular volumes were significantly lower on day 1 and day 2 than baseline in both term and preterm infants. Median (interquartile range) end systolic and diastolic volumes for term infants on days 0,1 , and 2 were 1.04 (0.88$1.44), 0.82(0.70-1.03), 0.92(0.72-0.97) \mathrm{ml} / \mathrm{kg}$ and $2.21(2.10-2.75), 2.05(1.81-2.38), 1.91$ $(1.81-2.13) \mathrm{ml} / \mathrm{kg}$ respectively. In preterm infants the values were $1.09(0.91-1.16), 0.72$ $(0.54-0.91), 0.61(0.54-0.76) \mathrm{ml} / \mathrm{kg}$ and $2.09(1.71-2.25), 1.47(1.23-1.98), 1.43(1.22-1.78)$ $\mathrm{ml} / \mathrm{kg}$ respectively.

Conclusion: Right ventricular volume decreases over the first 2 days of life in healthy term and preterm infants.
T he right ventricle is the dominant ventricle in utero. ${ }^{1-3}$ It has a larger cardiac output, receives more of the venous return, and has a larger volume than the left ventricle. ${ }^{1-4}$ After birth, the left ventricle enlarges, ${ }^{5}$ and left ventricular output exceeds right ventricular output ${ }^{67}$ until closure of the ductus arteriosus. ${ }^{7}$ Corresponding changes in right ventricular dimensions and function during the transitional circulation remain uncertain.

Pulmonary hypertension is associated with increased morbidity and mortality in cardiorespiratory disorders such as persistent pulmonary hypertension of the newborn and respiratory distress syndrome. ${ }^{8}$ Right ventricular pathophysiology is potentially important in these conditions. The ability of the right ventricle to maintain adequate pulmonary blood flow despite increased pulmonary vascular resistance may be critical for optimal oxygenation. However, there are few published data on right ventricular volumes or function in healthy term newborn infants and none in preterm healthy infants.

Two dimensional echocardiography has been widely used to determine ventricular dimensions and function in infants and children with and without structural heart disease. ${ }^{9}$ Measurements of right ventricular volume have been successfully validated using echocardiography with magnetic resonance imaging, which is generally accepted as the "gold standard". ${ }^{10} 11$

Our aims in this study were twofold: firstly, to evaluate the practicability and repeatability of two different echocardiographic methods for calculating right ventricular volumes in newborn infants; secondly, to follow changes in right ventricular volume during the first 48 hours of life in healthy term and preterm infants using two dimensional echocardiography.

\section{METHODS \\ Patients}

Healthy term infants were recruited from the postnatal wards. Premature infants were recruited from the neonatal unit if they had no cardiorespiratory distress. Three echocardiographic examinations were performed on each infant by a single trained observer (SJC). Median (interquartile range) age in hours at each examination was 5 (4-6) , 26 (24-29) and 49 (47-51) on days 0,1 , and 2 respectively. All infants were examined during quiet respiration or while asleep. Birth weight, gestational age, mode of delivery, Apgar scores, and cord acid base status were recorded from maternal and infant case notes. The local research ethics committee approved the study, and prospective written parental consent was obtained.

\section{Echocardiographic imaging}

The GE Ultrasound CFM 800 (GE Ultrasound, Bedford, UK) was used for all examinations. This incorporated a $5-10 \mathrm{MHz}$ multifrequency imaging transducer, colour flow mapping, and pulsed wave and continuous wave Doppler. The images obtained during the examination were stored in an integrated digital archiving system (Echopac, version 5.3; GE Ultrasound). A complete two dimensional and Doppler examination was performed to exclude structural heart disease, and to assess the patency and flow characteristics through the ductus arteriosus. ${ }^{12} 13$ The right ventricle was imaged using an apical four chamber view with the septum as vertical as possible, the tricuspid valve as horizontal as possible, and the apex in view (fig 1). ${ }^{10}$ A simultaneous electrocardiogram was also recorded.

\section{Image analysis}

Stored images were analysed by the same observer (SJC). The digital images were scrolled through to identify end systolic and end diastolic frames, using the electrocardiograph to help 

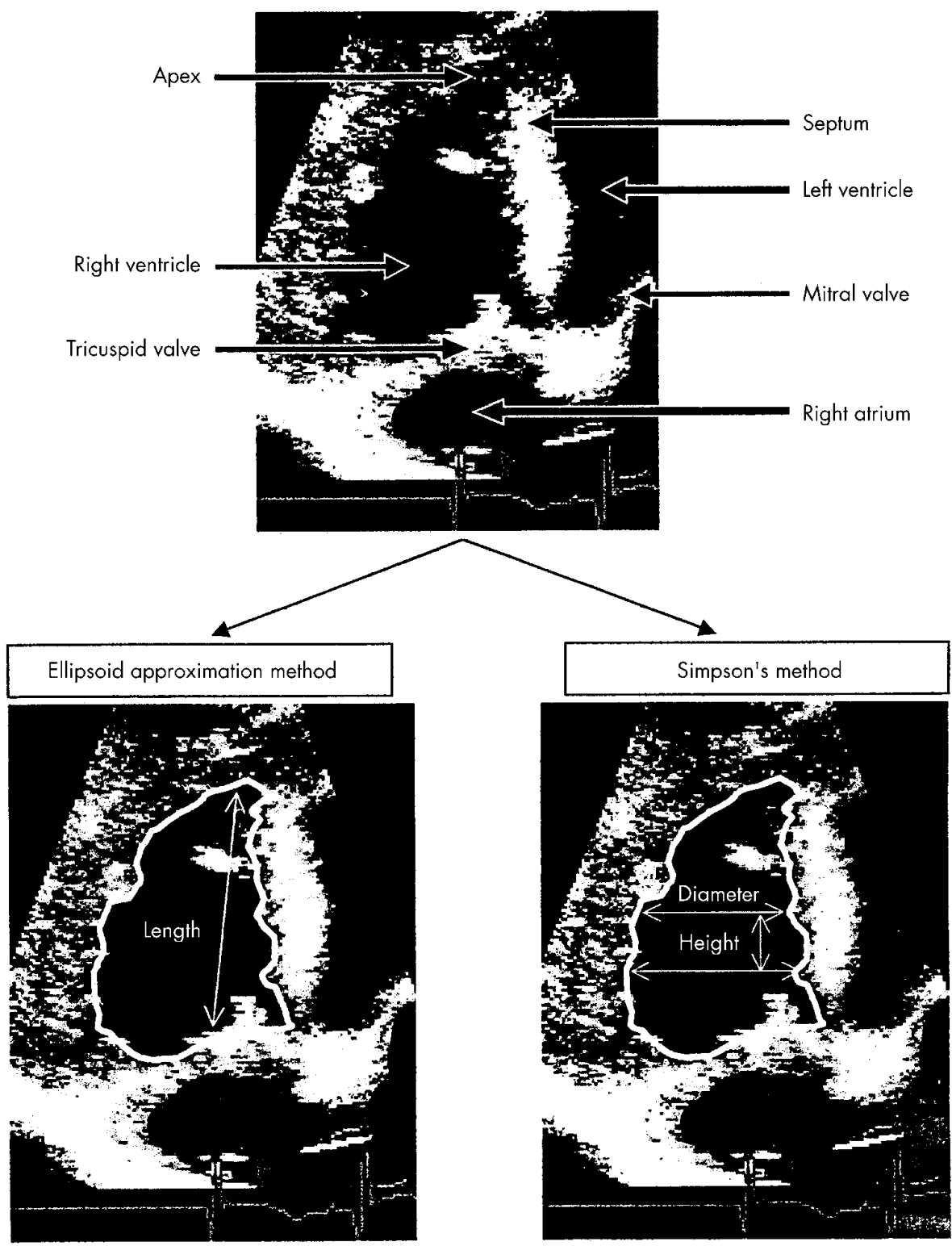

Figure 1 An echocardiographic image of the right ventricle from the apical four chamber view, taken at end systole with the tricuspid valve closed. For the ellipsoid approximation method, the internal margin is traced using planimetry and the length of the ventricle is measured. For the Simpson's method the ventricle is sliced into 20 equal discs of known height and diameter.

guide timing of end systole (T wave) and end diastole (start of the QRS complex). The boundaries of the right ventricle were traced using the integrated trackball over a minimum of five consecutive cardiac cycles, to allow for respiratory variation in ventricular filling (fig 1). ${ }^{14}$ Computer algorithms allowed calculation of the mean end systolic and end diastolic volumes. Two mathematical models were used to estimate right ventricular volumes (see equations $1 \& 2$ ):

Monoplane ellipsoid approximation method ${ }^{9}$

$$
\frac{8 \times \pi \times \text { area }^{2}}{3 \times \text { length }}
$$

Monoplane Simpson's stacked discs method ${ }^{9}$

$$
\sum_{20}^{1} \frac{\pi \times \text { height } \times \text { diameter }^{2}}{4}
$$

The measured volumes were used to calculate the stroke volume (diastolic volume-systolic volume). ${ }^{9}$ The right ventricular stroke volume was used to calculate the right ventricular output (stroke volume $\times$ heart rate) ${ }^{9}$ and the ejection fraction (stroke volume/diastolic volume). In addition, in a subgroup of infants the right ventricular output was also estimated using Doppler ultrasound examination of the flow characteristics in the pulmonary artery ${ }^{15}$ in order to compare values with right ventricular output derived from measurements of right ventricular volume.

\section{Repeatability studies}

In another subgroup of babies, separate repeat images of the right ventricle were obtained. These images were recorded during the same examination after an interval of about five minutes. They were analysed by the same single observer to assess intraobserver repeatability.

\section{Statistical analysis}

Right ventricular volumes were standardised for variations in birth weight and are expressed as $\mathrm{ml} / \mathrm{kg}$. Numerical data are 


\begin{tabular}{|c|c|c|c|c|}
\hline \multirow[b]{2}{*}{ Total infants } & \multicolumn{2}{|l|}{ Term } & \multicolumn{2}{|c|}{ Preterm } \\
\hline & 18 & & 17 & \\
\hline Males & 7 & $(39 \%)$ & 10 & $(59 \%)$ \\
\hline Gestation (completed weeks) & 39 & $(38-41)$ & 33 & $(31-34)$ \\
\hline Birth weight (kg) & 3.35 & $(3.00-3.45)$ & 1.74 & $(1.44-2.00)$ \\
\hline Caesarean section & 9 & $(50 \%)$ & 15 & $(88 \%)$ \\
\hline Apgar at 5 minutes & 10 & $(10-10)$ & 9 & $(9-10)$ \\
\hline Cord pH & 7.33 & $(7.28-7.35)$ & 7.36 & (7.32-7.38) \\
\hline Cord base excess & -3.8 & $(-1.6$ to -5.1$)$ & -1.4 & $(-0.5$ to -2.6$)$ \\
\hline
\end{tabular}

Values are expressed as number (\%) or median (interquartile range).

presented as median (interquartile ranges). Intraobserver repeatability was assessed using the coefficient of repeatability as described by Bland and Altman. ${ }^{16}$ The mean of the paired measurements was compared with the difference between the paired measurements, and is expressed as a percentage. The most repeatable method was chosen for subsequent analysis of right ventricular volumes. Serial measurements over time in individual infants were compared using Friedman's two way analysis of variance. ${ }^{17}$ Comparison between the two methods of determining right ventricular output was performed by calculating the limits of agreement ${ }^{16}$ and Spearman's rank correlation coefficient. Comparison between groups at a given time point used the Mann-Whitney U test. A p value of less than 0.05 was taken as being significant.

We estimated that a sample size of 16 infants in each group at each time point would allow the detection of a change in volume of one standard deviation from the baseline value ( $80 \%$ power at a $5 \%$ significance level).

\section{RESULTS}

\section{Patients}

Twenty three healthy term infants were recruited, five of whom were discharged before the final examination, leaving 18 infants who had a complete set of examinations. Seventeen healthy premature infants were recruited, all of whom completed the study. All of the 105 completed examinations produced images of sufficient quality for analysis. In none of the infants was a congenital heart defect identified. Table 1 shows details of the infants studied. Although there was no significant difference in the heart rates between examinations in each group, premature infants had a significantly faster heart rate at each examination than the term infants (table 2). There was no correlation between gestation and volumes corrected for birth weight. All infants had a reducing arterial duct diameter over the three examinations (table 2). Twelve infants, five of whom were preterm, had an open duct with pure left to right flow on day 1 . Three infants from each group had residual left to right flow detectable on colour flow mapping on day 2, with a median diameter of $0.21 \mathrm{~cm}$ (range $0.06-0.27$ ) in these six infants.

\section{Repeatability studies}

Fifteen term and preterm babies had paired examinations in which both systole and diastole were recorded and used for the repeatability analysis. The mean difference between measurements for Simpson's method was $2 \%$, with a coefficient of repeatability of $53 \%$. The mean difference for the ellipsoid method was also $2 \%$, with a coefficient of repeatability of $27 \%$. The ellipsoid approximation gave more repeatable results and was therefore the preferred method for analysis of ventricular volumes.

\section{Right ventricular output}

Right ventricular output was estimated in 17 term and preterm infants by both volume calculation and the pulmonary artery Doppler method. Median (interquartile range)
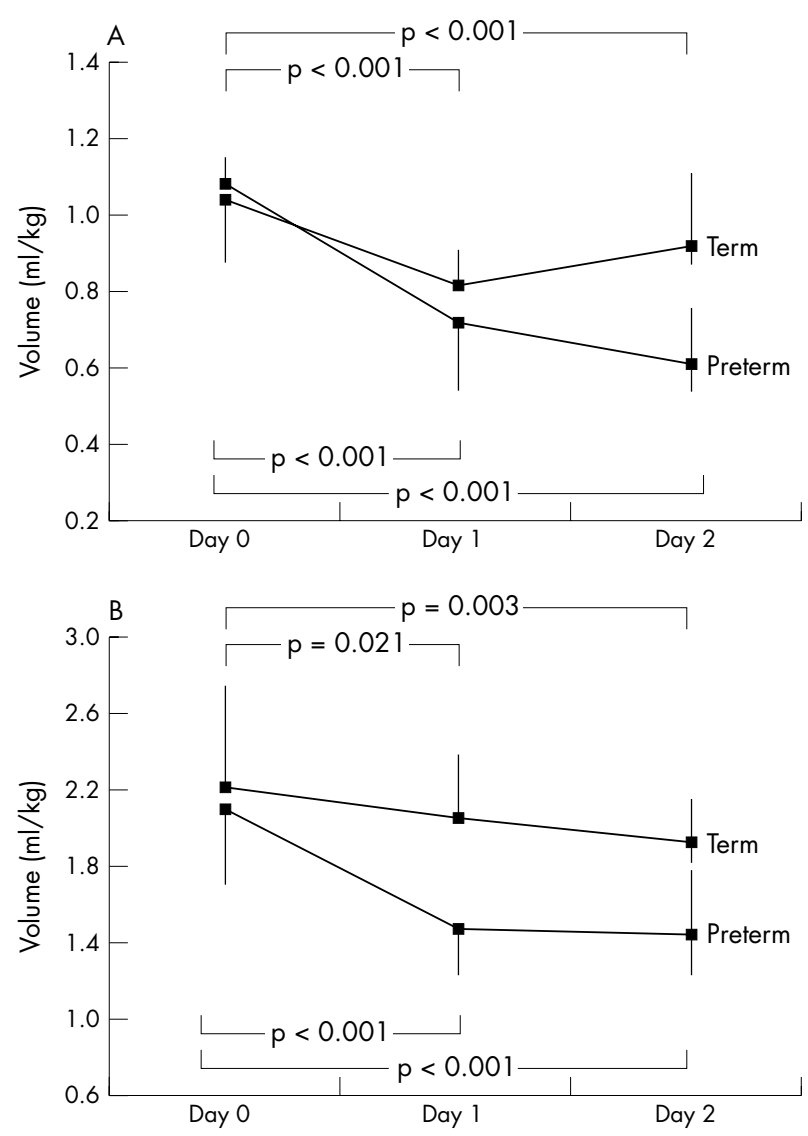

Figure 2 Change in right ventricular volumes over the first 2 days of life, showing medians and interquartile ranges, for $(\mathrm{A})$ systole and (B) diastole.

values were 135 (102 to 162 ) and 230 (168-322) ml/kg/min respectively. There was significant correlation between the two methods $(r=0.75, \mathrm{p}<0.001)$. The mean difference (standard deviation) between the two measurements was 119 (65) $\mathrm{ml} / \mathrm{kg} / \mathrm{min}$.

\section{Right ventricular volumes}

In both groups of infants, there were significant decreases in end diastolic and end systolic volumes by day 1 and these remained significantly lower on day 2 (fig 2 ). Table 2 shows right ventricular data. There were no significant differences in right ventricular systolic and diastolic volumes between term and preterm infants on day 0 . On day 1 preterm infants had a significantly smaller diastolic volume, and on day 2 both diastolic and systolic volumes were significantly smaller. Right ventricular stroke volume did not significantly alter over the study period in either term or preterm groups. However, right ventricular stroke volume was significantly smaller on day 1 and 2 in the preterm infants than the term infants. Right ventricular ejection fraction increased significantly by day 1 in the term infants. Right ventricular ejection fraction also tended to increase in the preterm group, although this was not significant. Right ventricular output did not significantly alter over the study period in either term or preterm groups. Right ventricular ejection fraction and output was not significantly different between the two groups.

\section{DISCUSSION}

In these healthy term and preterm infants, both end diastolic and end systolic right ventricular volumes decreased over the first 2 days of extrauterine life. There was no evidence of a significant change in the stroke volume or cardiac output of the right ventricle over time in each group. Stroke volume was 
Table 2 Right ventricular volume measurements

\begin{tabular}{|c|c|c|c|}
\hline & Day 0 & Day 1 & Day 2 \\
\hline \multicolumn{4}{|c|}{ End systolic volume $(\mathrm{ml} / \mathrm{kg})$} \\
\hline Term & $1.04(0.88-1.44)$ & 0.82 (0.70-1.03) & $0.92(0.72-0.97)$ \\
\hline Preterm & $1.09(0.91-1.16)$ & $0.72(0.54-0.91)$ & $0.61(0.54-0.76)$ * \\
\hline \multicolumn{4}{|c|}{ End diastolic volume $(\mathrm{ml} / \mathrm{kg})$} \\
\hline Term & $2.21(2.10-2.75)$ & 2.05 (1.81-2.38) & $1.91(1.81-2.13)$ \\
\hline Preterm & 2.09 (1.71-2.25) & $1.47(1.23-1.98) *$ & $1.43(1.22-1.78)$ * \\
\hline \multicolumn{4}{|c|}{ Stroke volume $(\mathrm{ml} / \mathrm{kg})$} \\
\hline Term & $1.15(0.99-1.36)$ & $1.11(0.98-1.35)$ & $1.08(0.92-1.30)$ \\
\hline Preterm & $1.04(0.79-1.21)$ & $0.84(0.72-0.98)$ * & $0.82(0.67-0.92) \dagger$ \\
\hline \multicolumn{4}{|c|}{ Ejection fraction } \\
\hline Term & $0.51(0.48-0.55)$ & $0.59(0.53-0.65) \ddagger$ & $0.57(0.49-0.59)$ \\
\hline Preterm & $0.49(0.41-0.56)$ & $0.53(0.49-0.59)$ & $0.57(0.51-0.61) \S$ \\
\hline \multicolumn{4}{|c|}{ Heart rate (beats/min) } \\
\hline Term & $112(107-120)$ & $119(111-125)$ & 115 (104-122) \\
\hline Preterm & $141(133-149) *$ & $140(132-143)^{*}$ & $128(122-141)^{*}$ \\
\hline \multicolumn{4}{|c|}{ Right ventricular output $(\mathrm{ml} / \mathrm{kg} / \mathrm{min})$} \\
\hline Term & $138(103-165)$ & $134(117-175)$ & $115(100-138)$ \\
\hline Preterm & 154 (115-171) & $112(95-145)$ & 107 (85-147) \\
\hline \multicolumn{4}{|c|}{ Colour flow map ductal diameter $(\mathrm{cm})$} \\
\hline Term & $0.39(0.27-0.42)$ & $0(0-0.25)$ & $0(0-0)$ \\
\hline Preterm & $0.36(0.26-0.41)$ & 0 (0-0.09) & $0(0-0)$ \\
\hline \multicolumn{4}{|c|}{ Duct detected on colour flow map } \\
\hline Term & $16 / 18(89 \%)$ & $7 / 18(39 \%)$ & $3 / 18(17 \%)$ \\
\hline Preterm & $17 / 17(100 \%)$ & $5 / 17(29 \%)$ & $3 / 17(18 \%)$ \\
\hline
\end{tabular}

significantly smaller in the preterm infants than the term infants on days 1 and 2, although right ventricular outputs were similar. This probably reflected the higher heart rate in the preterm group. There was a trend toward an increase in right ventricular ejection fraction with time, although this was only significant in the term infants.

\section{Perinatal changes}

Previous studies in human and animal fetuses have shown that the right ventricle is the dominant ventricle in utero, both in terms of stroke volume and cardiac output. ${ }^{12}$ At early gestations the right ventricle has thicker free muscular wall, with similar mass to the left ventricle ${ }^{18}$ and is stiffer than the term right ventricle. ${ }^{19}$ At term, the right ventricle remains less compliant than the left ventricle. ${ }^{14}$ After birth left ventricular stroke volume and output increase dramatically. ${ }^{15}$ This increase in left ventricular stroke volume is achieved predominantly through an increase in left ventricular end diastolic volume secondary to an increased pulmonary venous return. ${ }^{20}$ Pressure volume characteristics of the two ventricles are related through ventricular interaction in such a way that the volume of one ventricle is inversely related to the pressure in the other ventricle, because of the restraining effects of the pericardium. ${ }^{21}$ Therefore the likely result of an increase in left ventricular dimensions and pressure will be a reduction in right ventricular volumes. Although left ventricular volumes were not specifically measured in this study, our findings of a decrease in right ventricular end systolic and diastolic volume over the first two days of life are consistent with this hypothesis.

\section{Changes in right ventricular volumes}

In our study there was no significant change in right ventricular output or stroke volume despite a reduction in right ventricular end diastolic volume over the first 2 days of life. The right ventricular stroke volume and output may remain unchanged because there is a concomitant decrease in right ventricular end systolic volume, probably mediated by the fall in afterload following birth. ${ }^{22}$ There were no significant differences in right ventricular volume between the preterm and term infants on day 0 . Over the next two examinations, the preterm right ventricle was significantly smaller in both systole and diastole compared with the term infants. It may be that the morphology of the preterm heart, with a thinner walled left ventricle and a functionally hypertrophied thicker walled right ventricle, ${ }^{18}$ accentuates the changes seen after delivery in the term infants. In addition, the right ventricle is less compliant than the left ventricle ${ }^{14}$ in neonates, and this is more pronounced at earlier gestations perhaps contributing to the more rapid involution of the right ventricle seen in these premature infants.

\section{Other studies}

Our study is similar in design to that of Tamura et $a l,{ }^{23}$ but has produced conflicting results. In term infants, they showed an increase in right ventricular end diastolic volume, with no change in end systolic volume, leading to an increase in right ventricular stroke volume. However, the volumes reported were 3-4-fold smaller than those previously described. ${ }^{4}$ Using a different mathematical model, we found right ventricular volumes much closer to estimates in near term human fetuses. ${ }^{4}$ Furthermore, previous studies of human fetuses and newborns using $M$ mode echocardiography have shown a decrease in the right ventricular dimensions after birth. ${ }^{5425}$

\section{Echocardiographic assessment of right ventricular volumes}

Several studies have validated ultrasound assessment of cardiac volumes against invasive angiography, magnetic resonance imaging, and ventricular cast formation in both infant humans and animals. ${ }^{10}{ }^{1126-28}$ Ultrasound does tend to produce consistently lower volume estimates than magnetic resonance imaging. ${ }^{10}$ However, studies have shown this to be a systematic difference and therefore applicable for the assessment of trends. ${ }^{10}{ }^{11}$ We also observed a significant correlation between the two measures of right ventricular output, although in most cases the Doppler derived ventricular output was larger than that estimated from volume calculations. This reinforces the finding from validation studies that calculations of right ventricular volume systematically underestimate the true value. ${ }^{10}$

Assessment of changes in ventricular volume is likely to be preferable to measurements of changes in a single dimension, such as transverse diameter, because of the complex geometry 
of the right ventricle. ${ }^{24}$ In addition, we avoided reporting changes in the right ventricular area measured by planimetry because, unlike volume estimation, these measurements have not been validated. We compared two ultrasound methods of volume estimation to find the most practicable and repeatable. Although time consuming, both methods were relatively simple to perform and produced images of suitable quality for measurement and subsequent analysis. The coefficient of repeatability for the ellipsoid method was lower than that of the Simpson's method, making the ellipsoid method favourite for estimating right ventricular volume. A coefficient of repeatability of $27 \%$ is similar to the reported intraobserver repeatability for other research methods in cardiorespiratory physiology. ${ }^{29} 30$

\section{Clinical relevance}

Failure of normal cardiovascular adaptation, with persistently elevated pulmonary vascular resistance and pulmonary hypertension, is important in the pathophysiology of persistent pulmonary hypertension of the newborn and respiratory distress syndrome. ${ }^{81}$ Right ventricular dysfunction in the face of increased afterload may compromise pulmonary blood flow. Information about changes in right ventricular volumes at birth and in the early neonatal period may give valuable insights into the pathophysiological mechanism of hypoxaemic respiratory failure in these conditions. Although a number of studies have investigated left ventricular function in newborn infants with respiratory failure, ${ }^{32} 33$ there is little published work on right ventricular performance. Low right ventricular output (as a component of a biventricular low output state) is associated with severe respiratory distress syndrome and is almost universal in infants who subsequently die. ${ }^{15}$ The relative importance and contribution of right ventricular dysfunction in determining low right ventricular output in such infants remains unknown.

In summary, our study provides reference values for right ventricular volumes in healthy term and preterm infants. We believe that these are essential before assessing right ventricular function in neonates with cardiorespiratory disorders. We have also shown that the right ventricular systolic and diastolic volumes decrease within the first 48 hours of birth, but that right ventricular output remains unchanged. We speculate that involution of the right ventricle may be secondary to the increase in left ventricular size, through the effects of ventricular interaction.

\section{ACKNOWLEDGEMENTS}

Funding came from the North West National Health Service Executive Research and Development Reactive Funding Scheme and GE Ultrasound, Bedford, UK.

\section{Authors' affiliations}

S J Clark, C W Yoxall, N V Subhedar, Neonatal Unit, Liverpool Women's Hospital, Liverpool L8 7SS, UK

\section{REFERENCES}

1 Kenny JF, Plappert T, Doubilet $P$, et al. Changes in intracardiac blood flow velocities and right and left ventricular stroke volumes with gestational age in the normal human fetus: a propspective Doppler echocardiographic study. Circulation 1986;74:1208-16.

2 Teitel DF, Iwamoto S, Rudolph AM. Effects of birth related events on central blood flow patterns. Pediatr Res 1987;22:557-66.

3 Smolich JJ, Berger PJ, Walker AM. Interrelation between ventricula function, myocardial blood flow and oxygen consumption at birth in lambs. Am J Physiol 1996;270:H741-9.

4 Schmidt KG, Silverman NH, Hoffman JIE. Determination of ventricular volumes in human fetal hearts by two dimensional echocardiography. Am J Cardiol 1995:76:1313-16.

5 Veille JC, Hanson R, Steele L, et al. M-mode echocardiographic evaluation of fetal and infant hearts: longitudinal follow up study from intrauterine life to year one. Am J Obstet Gynecol 1996;175:922-8.

6 Gessner I, Krovetz J, Benson RW, et al. Hemodynamic adaptations in the newborn infant. Pediatrics 1965;36:752-62.

7 Emmanouilides GC Moss AV, Monset-Couchard M et al. Cardiac output in newborn infants. Biol Neonate 1970;15:186-97.
8 Walther FJ, Benders $M$, Leighton JO. Early changes in the neonatal circulatory transition. J Pediatr 1993;1 23:625-32.

9 Feigenbaum H. Echocardiographic evaluation of cardiac chambers. In: Echocardiography. Lea \& Febiger, 1994;134-80.

10 Helbing WA, Bosch HG, Maliepaard C, et al. Comparison of echocardiographic methods with magnetic resonance imaging for assessment of right ventricular function in children. Am J Cardiol 1995;76:589-94.

11 Apfel HD, Shen Z, Boxt LM, et al. Three dimensional echocardiographic assessment of the right ventricular volume and function in patients with pulmonary hypertension. Cardiology in the Young 1997:7:317-24.

12 Evans N, lyer P. Longitudinal changes in the diameter of the ductus arteriosus in ventilated preterm infants: correlation with respiratory outcomes. Arch Dis Child Fetal Neonatal Ed 1995;72:F156-61.

13 Kluckow M, Evans N. Relationship between blood pressure and cardiac output in preterm infants requiring mechanical ventilation. J Pediatr 996; 129:506-12

14 Riggs TW, Rodriguez R, Snider AR, et al. Doppler echocardiographic evaluation of right and left ventricular diastolic function in normal neonates. J Am Coll Cardiol 1989;13:700-5.

15 Evans N, Kluckow M. Early determinants of right and left ventricular output in ventilated preterm infants. Arch Dis Child Fetal Neonatal Ed 1996;74:F88-94.

16 Bland JM, Altman DG. Statistical methods for assessing agreement between two methods of clinical measurement. Lancet 1986:1:307-10.

17 Altman DG. Relation between several variables. In: Practical statistics for medical research. Chapman \& Hall, 1991;325-64.

18 Saint John Sutton MG, Gewitz MH, Shah B, et al. Quantitative assessment of growth and function of the cardiac chambers in the normal human fetus: a prospective longitudinal echocardiographic study. Circulation 1984;69:645-54

19 Romero T, Covell J, Friedman WF. A comparison of pressure volume relations of the fetal, newborn and adult heart. Am J Physiol 1972;222:1285-90.

20 Agata Y, Hiraishi S, Oguchi K, et al. Changes in left ventricular output from fetal to early neonatal life. J Pediatr 1991;119:441-5.

21 Pinson CW, Morton M, Thornburg KL. An anatomical basis for foetal right ventricular dominance and arterial pressure sensitvity. J Dev Physiol 1987;9:253-69.

22 Seear M, Webber S, Leblanc J. Descending aortic blood flow velocity as a noninvasive measure of cardiac output in children. Pediatr Cardiol 1994; 15:178-83

23 Tamura $M$, Harada K, lto $T$, et al. Changes in right ventricular volume in early human neonates. Early Hum Dev 1997;48:1-9.

24 Azancot A, Caudell TP, llen HD, et al. Analysis of ventricular shape by echocardiography in normal fetuses, newborns and infants. Circulation 1983;68:1201-1 1

25 Wladimiroff JW, Vosters R, McGhie JS. Normal cardiac ventricular geometry and function during the last trimester of pregnancy and early neonatal period. Br J Obstet Gynaecol 1982:89:839-44

26 Schmidt KG, Silverman NH, Van Hare GF, et al. Two dimensional echocardiographic determination of ventricular volumes in the fetal heart. Circulation 1990;81:325-33.

27 Silverman NH, Schiller NB. Cross sectional echocardiographic assessment of cardiac chamber size and ejection fraction in children. Ultrasound Med Biol 1984;10:757-69.

28 Silverman NH, Hudson S. Evaluation of right ventricular volume and ejection fraction in children by two dimensional echocardiography. Pediatr Cardiol 1983:4:197-204.

29 Skinner JR, Boys RJ, Heads A, et al. Estimation of pulmonary arterial pressure in the newborn: study of the repeatability of four Doppler echocardiographic techniques. Pediatr Cardiol 1996;1 1:360-9.

30 Aiton NR, Fox GF, Alexander J, et al. The influence of sleeping position on functional residual capacity and effective pulmonary blood flow in health neonates. Pediatr Pulmonol 1996:22:342-7.

31 Walther FJ, Benders M, Leighton JO. Persistent pulmonary hypertension in premature neonates with severe respiratory distress syndrome. Pediatrics 1992;90:899-904.

32 Gill $\mathbf{A B}$, Weindling AM. Echocardiographic assessment of cardiac function in shocked very low birth weight infants. Arch Dis Child Fetal Neonatal Ed 1993;68:F17-21.

33 Skinner JR, Hunter S, Hey EN. Haemodynamic features at presentation in persistent pulmonary hypertension of the newborn and outcome. Arch Dis Child 1996;74:F26-32.

\section{COMMENTARY}

The importance of the right ventricle is consistently underestimated. In conventional thinking about the cardiovascular system, the focus is invariably the function of the left ventricle. It is to be applauded that this study of Clark et al recognises the importance of the right ventricle and attempts to quantify measures of function in healthy term and preterm babies.

One reason for the absence of data about the function of the right ventricle is the lack of consistent landmarks that allow 
standardisation of function measures. Even in the left ventricle, interpretation of myocardial function measures is fraught with problems. In preterm babies, the traditional $\mathrm{M}$ mode measures, such as fractional shortening, are of limited use because of the reduced movement of the ventricular septum. ${ }^{1}$ An often ignored basic truth about the cardiovascular system is that a measurement at any one point in that system can be affected by events not only at the site of measurement but also occurring upstream and downstream of that site. For myocardial function, it is the preload and afterload conditions that most affect the interpretation of the findings. Sometimes myocardial function measures reflect the health of the myocardium, but in the transitional circulation they are more likely to reflect the load conditions. ${ }^{2}$ For example, a significant ductal shunt will improve measures of left ventricle contractility such as ejection fraction and fractional shortening, because the shunt will both increase the left ventricle preload and reduce the afterload. ${ }^{2}$ Left ventricular dysfunction has been measured in babies with severe respiratory distress/ pulmonary hypertension and interpreted as being a primary problem. ${ }^{3}$ However, this overlooks the fact that the preload of the left ventricle depends on blood getting through the lungs. If the resistance to pulmonary blood flow is very high (high right ventricular afterload), the right ventricular function will appear poor, and, because it will not be able to pump blood through the lungs, the preload on the left ventricle will be low and left ventricular contractility will also appear poor. In our own (unpublished) studies, nitric oxide can produce dramatic improvements in the function and outputs of both ventricles in some babies.

Clarke et al have shown that right ventricle end systolic and diastolic dimensions fall over the first 24 hours of life to a similar degree in a term and preterm cohort. The preterm babies were healthy and ranged from 31 to 34 weeks gestation; cardiorespiratory adaptation would be expected to occur relatively normally in such babies. ${ }^{4}$ Therefore these results may not be applicable to very preterm babies $(<30$ weeks gestation) in whom most preterm haemodynamic pathology is concentrated. ${ }^{5}$ The authors speculate that the decrease in dimensions of the right ventricle may reflect increase in size of the left ventricle and also the postnatal fall in pulmonary vascular resistance (afterload). The latter is not measured, but has been previously documented as falling gradually over the first 24 hours. The other factor not considered is the effect of incompetence of the foramen ovale on increasing right ventricular preload. Such incompetence is common in the early postnatal period particularly while there is still a ductal shunt. ${ }^{6}$

In our studies to date, we have derived little useful understanding from traditional measures of left ventricular contractility in newborns. Our focus has been more on flow measures, which we would argue is the important physiological outcome of myocardial function. Low systemic blood flow is common in the very preterm and is strongly associated with morbidity in these babies. ${ }^{5}$ Immaturity of myocardial function is likely to be a factor. We are currently analysing data on the relation between this low flow and the load independent measures of velocity of left ventricle circumferential shortening and wall stress. ${ }^{7}$ However, we do not have data on right ventricular function, which is just as important. The data of Clarke et al may provide an important framework on which to extend understanding of cardiac pathophysiology in the very preterm infant. However, these data also highlight that to interpret any measure in the cardiovascular system, it is important to know the limitations of that measurement and also what is happening upstream and downstream of the site where the measurement is taken.

N Evans

Department of Neonatal Medicine, Royal Prince Alfred Hospital, Camperdown, Sydney, NSW 2050, Australia; nevans@med.usyd.edu.au

\section{REFERENCES}

1 Lee LA, Kimball TR, Daniels SR, et al. Left ventricular mechanics in the preterm infant and their effect on measurement of cardiac performance. $J$ Pediatr 1992:120:114-19.

2 Harada K, Shiota T, Takahashi Y, et al. Changes in the volume and performance of the left ventricle in the early postnatal period. Early Hum Dev 1994;39:201-9

3 Kinsella JP, McCurnin DC, Clark RH, et al Cardiac performance in ECMO candidates: echocardiographic predictors for ECMO. J Pediatr Surg 1992;27:44

4 Evans NJ, Archer LNJ. Postnatal circulatory adaptation in term and healthy preterm newborns. Arch Dis Child 1990;65:24-6.

5 Kluckow M, Evans NJ. Low superior vena cava flow and intraventricular haemorrhage in preterm infants. Arch Dis Child Fetal Neonatal Ed 2000;82:F188-94.

6 Evans NJ, lyer P. Incompetence of the foramen ovale in preterm infants requiring ventilation. J Pediatr 1994;125:786-92.

7 Igarashi $\mathbf{H}$, Shiraishi $\mathrm{H}$, Endoh $\mathrm{H}$, et al. Left ventricular contractile state in preterm infants: relation between wall stress and velocity of circumferential shortening. Am Heart J 1994;127:1336-40. 